\title{
A Conape como estratégia de resistência do setor educacional brasileiro ao Golpe Uma experiência democrática em período de exceção
}

\author{
JOÃO ANTONIO CABRAL DE MONLEVADE* \\ Universidade Federal de Mato Grosso, Cuiabá, MT, Brasíl.
}

HAROLDO PEREIRA FERNANDES FILHO**

Confederação Nacional dos Trabalhadores em Educação, Brasília, DF, Brasil.

\section{Conferências nacionais de educação: introdução histórica}

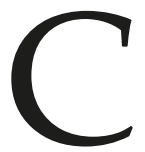

uritiba, em dezembro de 1927, abrigou evento que se autodenominou e que podemos considerar como a Primeira Conferência Nacional de Educação. Estiveram presentes delegados oficiais de 18 estados, e assinaram a ata da "sessão plena" - a do dia 20 - 218 "conferencistas", a maioria do próprio Paraná.

A Conferência se pautou por apresentação de teses sobre vários temas educacionais, desde os de suas políticas até os pedagógicos, identificados com os problemas do cotidiano das escolas.

Concordamos com quem considera a década de 1920 como os anos de efervescência cultural no Brasil, marcada pela Semana de Arte Moderna, realizada em São Paulo em 1922, mas também caracterizada pela fundação da Associação Brasileira de Educação (ABE), em 15 de outubro de 1924 no Rio de Janeiro, que estará presente dali por diante na organização de congressos e outros eventos educacionais, inclusive desta I Conferência. Segundo os próprios estatutos da ABE, ela buscava aglutinar os esforços de todos aqueles que acreditavam ser possível transformar o País pela educação, promovendo, "através de campanhas educacionais, uma reforma na mentalidade das elites."

A ABE reunia médicos, advogados, engenheiros e outros profissionais. Contudo, da Primeira Conferência, participaram principalmente professores e gestores da educação

* Sociólogo e educador. Doutor em Educação pela Universidade Estadual de Campinas. Professor aposentado da Universidade Federal de Mato Grosso e consultor legislativo aposentado do Senado Federal. Ex-dirigente da Confederação dos Professores do Brasil (CPB, atual CNTE), foi membro do Conselho Nacional de Educação (1996-2000). E-mail: professormonlevade@gmail.com.

** Sociólogo, mestre em sociologia política pela Universidade de Brasília e especialista em Gestão Pública pela Escola Nacional de Administração Pública. Ex-assessor técnico do Departamento Intersindical de Estatística e Estudos Socioeconômicos (Dieese), atualmente está na assessoria técnica da Confederação Nacional dos Trabalhadores em Educação (CNTE). E-mail: haroldo@cnte.org.br. 
básica e superior. Uma de suas sessões foi, inclusive, abrilhantada por mais de trezentas(os) normalistas de Curitiba, futuros(as) mestres (as), que lotaram o Teatro Guaíra.

Embora a maioria das estudantes fosse do sexo feminino, todos os delegados eram homens: entre eles, cumpre registrar os nomes de Lourenço Filho, de São Paulo - um dos mais ativos reformadores do ensino e do currículo nas décadas de 1920 a 1940 -e Lysimaco Ferreira da Costa, do Paraná, que coordenou a parte pesada dos sete dias de trabalhos da Conferência.

Foram apresentadas, discutidas e votadas 113 teses. De acordo com o texto oficial que descreve a Conferência, publicado em livro editado pelo Inep em 1997, elas versavam sobre:

“1) A unidade nacional: pela cultura literária, pela cultura cívica, pela cultura moral.

2) A uniformização do ensino primário nas suas ideias capitais, mantida a liberdade de programas.

3) A criação de escolas normais superiores em diferentes pontos do País para preparo pedagógico.

4) A organização dos quadros nacionais, corporações de aperfeiçoamento técnico, científico e literário."

A variadíssima temática das teses, os termos acima citados do resumo e a dinâmica das discussões - em que sobressaiu o resultado de uma votação "que refletisse o modo de pensar da assembleia dos professores sobre o ensino da moral com base na ideia religiosa", aprovado por 117 presentes contra 86 - mostram o caráter democrático desta primeira Conferência, que pautou todas elas dali em diante. Nas conferências se "conferem" posições, se apresentam divergências de pensamento, procurando unificar propósitos em nome da educação nacional.

A esta primeira, sucederam rapidamente três conferências chamadas pela $\mathrm{ABE}$. Na IV Conferência, realizada em 1931 no Rio de Janeiro, tornaram-se hegemônicas as ideias da "educação nova", advogando seu caráter leigo e de profunda ação do Estado, que deveria garantir escola obrigatória, comum e gratuita para todos até os 18 anos.

Em 1930, o Brasil tinha sido sacudido por uma revolução política, que procurava superar o elitismo do Império e da República Velha. Nesta linha, funda-se em 1932 o Ministério da Educação e Saúde e, no mesmo ano, publica-se o Manifesto dos Pioneiros, assinado por três mulheres e 21 homens - entre os quais seu redator principal, o sociólogo Fernando de Azevedo. Ainda em 1932, realiza-se a V Conferência Nacional, em Niterói, seguida da VI, em Fortaleza, que trataram especificamente de sugestões para a Constituição que se anunciava e se elaborava.

A Constituição de 1934 manifesta, institucionalmente, os avanços da concepção democrática da educação e, timidamente, de sua gestão. Pela primeira vez se estabelece o dever da União de legislar sobre as diretrizes e bases da educação, de investir nela ao 
menos 10\% dos impostos (percentual idêntico das receitas municipais e dobrado nas estaduais) e de compor um Conselho Nacional da Educação, cuja principal tarefa é a de elaborar o Plano Nacional de Educação, a ser aprovado pelo Poder Legislativo. Obriga também os estados a terem seus conselhos de educação, além de "departamentos autônomos de administração de ensino": ecos, todos eles, das conferências e dos congressos de educação.

Entretanto, em 1937, Getúlio Vargas se torna ditador, abrigado por uma nova Constituição, de caráter autoritário e regressivo, que vai se estender às ações do MEC e das secretarias estaduais de educação, onde passam a vigorar ações burocráticas e centralizadas, inibindo, inclusive, a realização de novas conferências de educação.

Em 1959, treze anos depois da redemocratização do Brasil, pela Constituição de 1946, onde se restauraram alguns poucos princípios e garantias de democratização da educação - entre os quais o investimento mínimo de $10 \%$ da renda dos impostos federais e $20 \%$ dos estaduais e municipais na "manutenção e desenvolvimento do ensino" - alguns dos pioneiros de 1932 lideraram a redação de um novo Manifesto, assinado por 161 personalidades, das quais 34 eram mulheres. Registre-se que a proporção de mulheres passou de 10 para $20 \%$ - quando, no magistério público, já eram maioria. Na verdade, durante o Estado Novo, às conferências de cunho liberal e democrático tinham sucedido congressos pontificados por autoridades, o que vai, inclusive, se oficializar posteriormente, na Ditadura Militar, quando o marechal Castelo Branco edita o Decreto no 54.999, de 13 de novembro de 1964, determinando a realização anual de uma Conferência Nacional de Educação, a ser convocada pelo ministro da Educação. Com isso, esvaziaram-se também os congressos patrocinados pela ABE, como o XIII, em 1967.

Enquanto isso, o Brasil se urbaniza, as matrículas no $1^{\circ}$ grau de oito anos se multiplicam, as polêmicas com o $2^{\underline{0}}$ grau de profissionalização compulsória se radicalizam e a procura pela educação superior força a fundação de novas universidades públicas (federais e estaduais), bem como de milhares de cursos superiores privados: é a democratização pela base que se reanuncia nos finais dos anos 1970, com os movimentos sociais, o novo sindicalismo, a multiplicação de professores que se associam nos estados, o protagonismo dos estudantes. Se as conferências até ali eram desejáveis, passaram a ser necessárias e imperativas para a própria educação - tanto quanto o são as escolas.

\section{Marcos normativos e legais das conferências nacionais}

Neste texto faz-se necessário dar uma notícia sobre leis e normas que presidem as manifestações coletivas no campo educacional, entre as quais se destacam as conferências.

É na produção do Poder Legislativo que vamos buscar alguns dados mais recentes, do século XXI, como fizemos nos parágrafos anteriores em relação ao século XX. 
As menções explícitas a conferências se dão no Projeto de Lei do PNE, de 2000, intitulado pelos autores como "da Sociedade Brasileira". Mas cumpre registrar suas bases: os artigos 206, 211 e 214 da Constituição de 1988. No primeiro, entre os princípios do ensino em geral, se proclama o da gestão democrática do ensino público, o qual, no contexto da construção do sistema nacional de educação que subjaz aos sistemas estaduais e municipais de ensino do Art.211, constitui "plataforma de lançamento" de futuros eventos coletivos: as conferências que ficam "subentendidas" nas expressões e frases que tratam do Plano Nacional de Educação do Artigo 214, formulado pelo constituinte Florestan Fernandes.

O primeiro PNE, sancionado em 9 de janeiro de 2001, como anexo da Lei nº 10.172, previsto pela Lei de Diretrizes e Bases da Educação (LDB), de 1996, foi fruto de dois projetos: o primeiro, dos deputados do Partido dos Trabalhadores; o segundo, de lavra do Poder Executivo. Ambos são precedidos de intensa mobilização da sociedade, no contexto da redemocratização a que já aludimos. Entre 1980 a 1991 se sucederam seis conferências brasileiras de educação, as CBE de São Paulo (1980), Belo Horizonte (1982), Niterói (1984), Goiânia (1986), Brasília (1988) e a de 1991, novamente em São Paulo. Daí por diante se celebraram os congressos nacionais de educação (Coned) em Belo Horizonte (1996 e 1997) e em Porto Alegre (1999). O ambiente educacional estava saturado de ideais democráticos; mas subsistiam as tensões para colocar em prática seus processos.

Conforme descreve Jamil Cury, a Lei 10.172 reflete preponderantemente os termos da proposta do Executivo, embora alguns dispositivos da Proposta da Sociedade Brasileira tenham sido incorporados ao texto. Quanto à gestão e à avaliação do PNE - onde seria fundamental o papel das conferências - a Lei 10.172 delega essas funções, por mecanismos coletivos fragmentados, aos conselhos escolares e às entidades representativas dos secretários estaduais e municipais de educação (Consed e Undime). Ao final de um texto com mais de 200 metas, uma conclamação retórica celebra a participação social e exorta todos a cumprir os termos do Plano. Acompanhou a sanção uma mensagem de veto do Presidente FHC, verdadeiro "balde de água fria”, que anulou a meta dos 7\% do PIB em educação e cortou as possibilidades de efetiva ampliação de recursos financeiros, a exemplo da complementação da União ao Fundef em valores decrescentes. $\mathrm{O}$ que tivemos de positivo dali por diante foi a perseverança de setores progressistas da sociedade em realizar os Coned de 2003 em São Paulo e de 2004 em Recife. Mas aí já é outra história, com o País presidido pelo operário Lula e com um Ministério da Educação sob responsabilidade do Partido dos Trabalhadores.

O PNE II teve, além da longa gestação nos anos anteriores, dois berços: a Conae de 2010, realizada em Brasília no final de abril, e o Projeto de Lei nํ 8.035, que o Executivo protocolou na Câmara dos Deputados aos 20 de dezembro de 2010.

A Conae de 2010, ápice de um processo que incluiu a celebração da Coneb em 2008, foi um evento de grande impacto no País, porque, pela primeira vez, celebrou-se depois 
da realização de conferências municipais e estaduais que envolveram milhões de educadores, estudantes e pesquisadores em torno de um texto-referência elaborado pelo MEC. Concluídos os seus trabalhos, um grupo seleto de gestores e acadêmicos se esforçou em delinear os termos do Projeto de Lei que continha o PNE II, com uma introdução operacional e o anexo de 20 metas com suas respectivas estratégias. O Art.6o do PL marca a inserção que se pensava definitiva das conferências nacionais na legislação brasileira:

“Art. 6- A União deverá promover a realização de pelo menos duas conferências nacionais de educação até o final da década, com intervalo de até quatro anos entre elas, com o objetivo de monitorar e avaliar a execução do PNE 2011-2020 e subsidiar a elaboração do Plano Nacional de Educação para o decênio 2021-2030.

Parágrafo único. O Fórum Nacional de Educação, a ser instituído no âmbito do Ministério da Educação, articulará e coordenará as conferências nacionais previstas no caput."

É no texto do ministro, entregue ao presidente da República no dia 3 de novembro de 2010, que se torna cristalino o pensamento da Conae e do MEC em relação às conferências nacionais de educação. "O PNE deve ser resultado de ampla participação e deliberação coletiva da sociedade brasileira, por meio do envolvimento dos movimentos sociais e demais segmentos da sociedade civil e da sociedade política, em diversos processos de mobilização e de discussão, tais como: audiências públicas, encontros e seminários, debates e deliberações das conferências de educação. Dessa forma, as conferências municipais, estaduais e nacionais de educação devem ser consideradas como espaços de participação da sociedade na construção de novos marcos para as políticas educacionais e, nesse sentido, sejam compreendidas como loci constitutivos e constituintes do processo de discussão, elaboração e aprovação do PNE." Trata-se, nada mais, nada menos, do que o início de definição legal de um poder legislativo educacional, na linha de democracia direta, garantida pela Constituição.

A tramitação do PNE II no Congresso arrastou-se por mais de três anos, mas foi garantida a realização da Conferência Nacional em 2014, ano em que foi aprovada a Lei $\mathrm{n}^{\mathrm{o}}$ 13.005, que fixou o PNE com vigência até 2024. Na redação final do Plano ficaram garantidas, na Meta 19, as seguintes estratégias que consolidam as conferências nacionais de educação, posteriormente articuladas a conferências subnacionais nos planos estaduais e municipais de educação, aprovados, na maioria, até 25 de junho de 2015:

"Art. 6 - A União promoverá pelo menos duas conferências nacionais de educação até o final do decênio, precedidas de conferências distrital, municipais e estaduais, articuladas e coordenadas pelo Fórum Nacional de Educação, instituído nesta Lei, no âmbito do Ministério da Educação.

$\S 1^{0}$ O Fórum Nacional de Educação, além da atribuição referida no caput:

I - acompanhará a execução do PNE e o cumprimento de suas metas;

II - promoverá a articulação das conferências nacionais de educação com as conferências regionais, estaduais e municipais que as precederem." 
Estes dispositivos iniciais foram confirmados na estratégia 3 da Meta 19 do PNE, que trata da gestão democrática da educação, nos seguintes termos: "Incentivar os Estados, o Distrito Federal e os Municípios a constituírem Fóruns Permanentes de Educação, com o intuito de coordenar as conferências municipais, estaduais e distrital, bem como efetuar o acompanhamento da execução deste PNE e de seus Planos de Educação".

O MEC não se omitiu nestas tarefas, desde o segundo semestre de 2014 até maio de 2016. Dedicou-se a ela a Secretaria de Articulação com os Sistemas de Ensino (Sase), por meio de um corpo de avaliadores especificamente contratados e treinados para as ações de incentivo, de orientação e acompanhamento. Entretanto, assim como muitas metas do PNE I foram solenemente ignoradas pelas autoridades educacionais, depois de aprovados os planos estaduais e municipais, a maioria dos/as secretários/as de educação continuou a pautar suas ações pelas antigas rotinas e por posturas de subserviência aos governadores e prefeitos, bem como por indiferença diante das metas e estratégias de seus planos e de luta por recursos extra do MEC para socorrer necessidades imediatas. Como se verá nas próximas seções deste texto, a ruptura da normalidade democrática com o impedimento da presidenta legitimamente eleita pode ter sido a "pá de cal" em relação ao cumprimento do PNE, dos PEE e dos PME Pergunta-se: as conferências de educação terão sido bem plantadas nos governos Lula e Dilma e podem ser a esperança dos que nela se construíram como gestores coletivos da educação nacional?

\section{O golpe de 2016 e o Fórum Nacional Popular de Educação (FNPE)}

No dia 12 de maio de 2016, o Brasil vive uma das experiências mais esdrúxulas de sua história política: o afastamento de uma presidenta legitimamente eleita pelo voto popular, em um processo que ficou conhecido como golpe parlamentar/jurídico/midiático, abala as estruturas da jovem democracia brasileira. Um golpe interditou um ciclo de governos populares no País a partir de um discurso travestido de legalidade, mas eivado de componentes persecutórios e justificado a partir de um crime inventado.

O impeachment da presidenta Dilma Rousseff ganhou ares de complô político, que teve como ingredientes doses de misoginia (pelo fato de termos a primeira mulher exercendo o cargo mais alto do País), de interesses externos camuflados (pela participação cada vez mais evidente dos Estados Unidos na desestabilização de nossa economia) e de uma aliança nacional formada pelos mais retrógrados interesses (composta por setores políticos, econômicos e sociais tradicionais brasileiros. A partir desse processo de interrupção democrática, o Brasil passou a viver um período de retirada de direitos sociais consagrados, ascensão de pautas conservadoras em todos os campos da vida social e política, de ataque à base econômica nacional com a destruição de grandes empresas, asfixia do modelo de financiamento sindical e toda uma espiral de violência que culminou 
com um processo de assassinatos e prisões políticas arbitrárias. Isso em pleno século XXI. Até o momento da elaboração deste texto, mantem-se o calendário eleitoral, em que pese estar o principal candidato, líder em todas as pesquisas de opinião, encarcerado por um processo judicial mequetrefe, também feito em conluio com o poder judiciário brasileiro e a grande mídia corporativa ${ }^{1}$.

Esse quadro avassalador atingiu com força o setor da educação, arena desde muito disputada por interesses privados, que encontraram adesão e eco nos que tomaram de assalto o poder do governo central em 2016. As medidas do governo de Michel Temer se constituíram em verdadeiros ataques à educação brasileira por meio de ações múltiplas, que objetivaram, desde sempre, combalir os alicerces que vinham sendo construídos nas políticas educacionais, retratadas anteriormente neste artigo. Como já aqui indicado, os avanços das políticas públicas de educação na última década no Brasil culminaram com a aprovação do PNE em junho de 2014, um instrumento de planejamento governamental que estabeleceu e pactuou metas para o próximo decênio (2014-2024). Todo esse arcabouço normativo foi oriundo da Conferência Nacional de Educação, a Conae-2010, precedida por inúmeras conferências municipais, estaduais e distrital, que se repetiram no ano de 2013, durante a tramitação do Projeto de Lei no 8.035/2010, que originou a Lei $n^{0}$ 13.005/2014 (Lei do PNE - 2014-2024). Foram essas ações que também fomentaram, em grande medida, a elaboração de planos municipais, estaduais e distrital de educação, envolvendo um conjunto enorme de entidades educacionais da sociedade civil organizada.

Desde o golpe de 2016, no entanto, os ataques promovidos à educação pública pelo governo ilegítimo são inúmeros e contundentes: já em dezembro de 2016, poucos meses depois da confirmação pelo Senado Federal do afastamento de Dilma Rousseff, o governo brasileiro fez aprovar a Emenda Constitucional nº 95, que impôs à sociedade brasileira o congelamento dos gastos públicos da União, inclusive os referentes à educação, por um período de 20 anos. Com essa medida, o governo comprometeu o cumprimento de várias metas pactuadas no PNE, já que o desdobramento natural da asfixia orçamentária e financeira preconizada pela Emenda Constitucional interditava sua consecução. Paralelamente, no começo de 2017, uma proposta de Reforma do Ensino Médio foi aprovada, diminuindo a base do conhecimento e estimulando a privatização dessa etapa educacional. A reforma atacou o princípio da profissionalização do magistério brasileiro, já que prevê a possibilidade de contratação de professores por "notório saber" para lecionar na educação técnica e profissional.

Ainda em 2017, foi aprovada a lei da terceirização ilimitada (Lei 13.429), que confere aos gestores públicos a possibilidade de privatizar a escola por meio do fortalecimento da gestão escolar por organizações sociais, vislumbrando a contratação de profissionais sem concurso público e com remuneração abaixo do piso salarial profissional. A lei da terceirização ilimitada foi o prenúncio da Reforma Trabalhista (Lei 13.467), aprovada na 
sequência, e que também tem impacto na educação: a possibilidade de contratação de professores por trabalho intermitente tem como objetivo tácito o fim da legislação que garante horas extraclasse na jornada remunerada dos(as) professores(as).

Esse conjunto de ações criou um caldo de descontentamento no setor educacional público brasileiro, na medida em que as alterações legais foram realizadas de afogadilho, com pouquíssima participação social - movimento típico de governos sem legitimidade eleitoral. Afinal, toda essa agenda que estava a ser implementada no País não fazia parte do projeto político referendado nas eleições de 2014. Ao contrário, era a pauta abertamente defendida pelo projeto político derrotado nas urnas. Não demorou, portanto, para o governo Temer criar as condições para o desmantelamento de todos os espaços de controle social construídos com a aprovação do PNE. O principal deles era certamente o Fórum Nacional de Educação (FNE), órgão previsto em Lei, que tinha como principal atribuição, além da formulação das políticas públicas de educação, o acompanhamento das metas pactuadas no âmbito do PNE.

Em abril de 2017, por meio de seu Ministério da Educação, o governo editou a Portaria Ministerial n⿳ำ 577, que alterou e desfigurou a composição do FNE, cuja marca era a participação de importantes segmentos de todos os níveis da educação brasileira por meio de representações governamentais e de entidades da sociedade civil, de cunho acadêmico e sindical. Em uma ação desmedida e sem critérios, o MEC afastou várias entidades da sociedade civil daquele espaço, que sempre teve como princípio o diálogo do governo com a sociedade. A partir daí, com o incremento de uma agenda da década de 1990, inclusive com o retorno a postos chaves da gestão governamental no MEC de figuras públicas de governos passados, as entidades educacionais que faziam parte do Fórum Nacional de Educação, até aquelas que não foram atingidas pela Portaria, decidiram por esvaziar aquele espaço, outrora um espaço de diálogo social. O pano de fundo para essa decisão coletiva foi a percepção de que as entidades educacionais não poderiam se submeter ao arbítrio perpetrado pelo MEC contra o setor da educação. Se não bastasse a alteração da composição do Fórum, a Portaria ainda indicava que os novos membros deveriam passar pela aprovação prévia do gabinete do ministro, afrontando a autonomia das entidades da sociedade civil, balizada pelos princípios da auto representação, tão caros em espaços de diálogo social. Explicitamente, a reconfiguração do FNE tinha como objetivo retomar o controle do processo das conferências de educação, justamente quando se estava na iminência da realização da Conae 2018, para, assim, inviabilizar, a partir do esvaziamento de sua pauta e da protelação de sua data, sua realização antes das eleições gerais.

Isso porque, um dia antes da edição dessa Portaria, que desfigurou a composição do FNE, o MEC publicou um decreto, elaborado e discutido a portas fechadas do gabinete ministerial, e sem quaisquer consultas aos membros do Fórum, que alterava o calendário pactuado para a realização da Conae-2018. O Decreto Executivo de 26 de 
abril de 2017 mudava a data da realização da Conferência, indicando que ela seria realizada somente no segundo semestre de 2018. Ali estava claro que os objetivos do governo eram que a Conferência fosse realizada somente depois das eleições gerais marcadas para o segundo semestre.

Com as duas medidas tomadas de forma absolutamente autoritária, o afastamento de várias entidades da sociedade do FNE foi natural e, em grande medida, consolidou um movimento de resistência aos ataques diuturnamente perpetrados contra a educação pública brasileira pelo governo ilegítimo, fruto do golpe parlamentar. Criou-se, assim, por essas entidades, o Fórum Nacional Popular de Educação (FNPE), que nasceu com o objetivo de ser um instrumento estratégico de resistência do setor da educação ao desmonte brutal das políticas públicas da área promovido pelos golpistas. Inicialmente constituído por 26 entidades da sociedade civil, incluindo organizações sindicais, entidades estudantis e de pesquisa educacional, o FNPE tinha como objetivo e tarefa principais se constituir em espaço de pressão para que os planos nacional, estaduais, distrital e municipais de educação fossem verdadeiramente implementados, além de assumir e viabilizar a realização da Conferência Nacional Popular de Educação (Conape) para o ano de 2018, antes das eleições, conforme pactuado anteriormente.

A constituição do FNPE para a realização da Conape se colocou como a verdadeira trincheira de resistência para além dos aspectos mais corporativos e particulares da educação. Em seu manifesto de lançamento, a Conape sempre assumiu para si uma luta mais ampla em defesa da própria democracia roubada: "o movimento educacional necessita mostrar que o desenvolvimento da educação não se dá apenas no âmbito da luta educacional, mas também no enfrentamento à exclusão, à concentração de renda e às disparidades regionais e sociais, consequências de uma noção de desenvolvimento baseada no consumo, que acirra a desigualdade e à qual o combate exige ações políticas e sociais articuladas".

O FNPE, assim, ganhava cada vez mais musculatura, capilaridade e robustez nas suas proposições e intervenções no campo do debate das políticas educacionais. Dessa forma, resultado e desdobramento natural, o FNPE passou a arregimentar mais entidades do setor e também outras de atuação mais ampla e diversa, promovendo e ganhando, assim, mais adesões. $\mathrm{O}$ que começou como uma articulação de 26 entidades mais vinculadas ao debate propriamente educacional, hoje já aglutina e organiza a intervenção de 35 entidades da sociedade civil brasileira².

\section{Conferências populares de educação tomam conta do País: etapas municipais, estaduais, distrital e livres}

A consolidação do FNPE como espaço de resistência e contraponto aos desmandos do MEC praticados no âmbito do FNE fortaleceu a ideia, já em julho de 2017, de 
realizar uma grande Conferência Nacional Popular de Educação (Conape). O objetivo de organizar e realizar a Conape sempre foi no sentido de defender o legado construído pelas outras conferências de educação, em especial os desdobramentos da Conae-2014, que teve no Plano Nacional de Educação, instituído pela Lei Federal nº 13.005/2014, o resultado mais direto das discussões e debates travados no âmbito daquela conferência.

O PNE traduziu um esforço coletivo formidável de formulação de políticas públicas na área da educação. Estabeleceu diretrizes, metas e estratégias a serem perseguidas por todo o sistema confederativo brasileiro, comprometendo os municípios, os estados, o DF e a União na sua consecução. Esse comprometimento espelhou-se no sofisticado arranjo federativo que a política pública de educação no Brasil impõe a todos os entes. Os estados e municípios foram instados a elaborar seus planos municipais e estaduais, de modo a atender o prescrito no PNE. Em que pese uma leitura crítica desse movimento apontar as enormes lacunas e dificuldades que os gestores locais e movimentos sociais ligados à educação pelo País afora encontraram para a efetivação dessa normativa, nada apaga a história coletiva de sua construção.

Na própria convocatória à Conape, em documento redigido pela coordenação executiva do FNPE, composta por 12 entidades $^{3}$, era explícita a tentativa de fazer do movimento um instrumento para assumir as atribuições do FNE, que, naquele momento do golpe, estavam fadadas ao fracasso e a todo tipo de obstrução, em decorrência das ações e orientação da gestão do MEC. E para além mesmo das ações propriamente do MEC, a constituição do FNPE mostrava-se atenta ao atual contexto político mais amplo, como assinalado na carta-convocação: “O FNPE decidiu convocar a Conferência Nacional Popular de Educação (CONAPE 2018) como forma de organizar e manter a mobilização em torno da defesa do PNE, da necessidade de monitoramento das metas e da análise crítica das medidas que têm inviabilizado a efetivação do Plano, em especial, a aprovação da Emenda Constitucional 95/2016, que estabelece um teto de 20 anos aos gastos públicos federais, inviabilizando a consagração plena de todos os direitos sociais, especialmente a educação".

A partir daí, o FNPE passou a conclamar os fóruns estaduais, municipais e distrital de Educação a participar desse movimento de resistência ao desmonte promovido pelo governo ilegítimo. O FNPE assumiu para si um documento-referência, construído em cima dos mesmos eixos pactuados em 2016 pelas entidades no âmbito do FNE, ainda em sua formatação original. A ideia era de que esse documento pudesse se prestar ao debate público sobre a educação brasileira, de modo a fomentar as discussões acerca dos ataques promovidos pelo governo contra o sistema educacional. Era um chamado à participação popular e à retomada dos rumos das políticas públicas da educação em nosso país. A convocação do FNPE foi um primeiro movimento para aferir a adesão nos estados e municípios brasileiros quanto à ideia de promover uma conferência popular, paralela ao movimento oficial. 
A convocação do FNPE, por fim, ganhou adesão por todo o País. Representantes dos fóruns estaduais foram chamados a participar de uma primeira reunião em Brasília, no mês de agosto de 2017 e a participação, já naquela oportunidade, foi expressiva: com 36 presentes, a reunião contou com a representação de 15 coordenações estaduais dos fóruns ${ }^{4}$.

A primeira reunião foi muito importante para socializar as informações mais sensíveis no processo de rompimento com o Fórum Nacional da Educação golpista. No momento da edição do Decreto e da Portaria de abril, que, respectivamente, adiaram a Conae-2018 e desfiguraram sua composição, a coordenação do FNE estava sob a responsabilidade da sociedade civil, no consagrado sistema de rodízio, muito típico dos espaços de concertação e diálogo social. A alternância da coordenação rotativa do espaço era sempre pactuada entre governo e entidades da sociedade civil: de 2010 a 2014, o governo assumiu a coordenação do FNE; de 2014 a 2018, a coordenação ficaria sob responsabilidade do segmento da sociedade civil, que indicou a Confederação Nacional dos Trabalhadores em Educação (CNTE) para cumprir a tarefa. Em abril de 2017, cabia ao professor Heleno Araújo Filho, representante da CNTE no FNE, a coordenação daquele espaço. Então, as informações compartilhadas por ele com todos os representantes estaduais serviram, sobretudo, para dirimir alguma resistência que alguns setores ainda apresentavam com a debandada articulada das entidades educacionais do espaço do FNE, que sempre contou com o maior apreço de todos por considerá-lo não um espaço de governo, mas uma arena de participação social na definição das políticas públicas de educação.

Heleno Araújo começou a reunião de agosto de 2017 explicitando a todos os motivos do rompimento com o FNE. Conforme relatório da reunião, ele ratificou o entendimento de que o FNE é resultado de uma política de Estado e que a luta inicial sempre foi pela revogação da Portaria Ministerial nº 577. O governo tinha como objetivo hegemonizar artificialmente o espaço, a partir da formação de uma maioria na composição do Fórum, ao destituir a participação de muitas entidades, que, agora, estavam ali representadas pelo FNPE. Lembrou a todos que, enquanto coordenador do FNE, foi muito insistente em se reunir com o representante do MEC para garantir o calendário das etapas municipais, estaduais e distrital das conferências de educação, de modo a assegurar a realização da Conae em 2018. Mas não encontrava eco naquela gestão do MEC, que não liberava os recursos orçamentários para garantir as etapas municipais, estaduais e distrital.

O que começou a ficar evidente, nas palavras de Heleno Araújo, "foi que todos os acordos firmados em reuniões com os representantes do MEC, até então solícitos em acolher as demandas colocadas pelo FNE, eram solenemente ignorados por outros setores do Ministério. Esse descompromisso do MEC com as garantias de realização das conferências municipais, estaduais e nacional de educação alcançou tal magnitude que o pleito do FNE foi levado, em certa altura e ocasião, ao próprio ministro da Educação, que, mesmo com as palavras de apoio iniciais 
às demandas do FNE, não dava prosseguimento a nenhuma demanda solicitada, em uma deliberada ação de protelação. A gota d'água de todo esse processo foi o debate da BNCC, que nunca foi encaminhado ao FNE e era dado somente de forma interna ao Ministério. Ao apresentar publicamente a proposta da BNCC, nunca apreciada pelo FNE, o MEC recebeu inúmeras manifestações contrárias àquele projeto, tanto no seu método de elaboração e discussão quanto no seu próprio mérito e conteúdo".

O relatório prossegue com o relato de Heleno na reunião: "diante dessa inação deliberada do MEC em dar prosseguimento às conferências de educação, um grupo de entidades vinculadas à educação, a partir da coordenação do professor Luiz Dourado, resolveu elaborar um documento-referência para a Conferência Nacional de Educação (Conae) que o MEC se empenhava em não realizar, apesar das palavras, e apenas palavras, em contrário. Em ato contínuo, e seguindo determinação expressa pelo próprio regimento do FNE, a coordenação deste Fórum decidiu por convocar uma reunião para os dias 20 e 21 de fevereiro deste ano de 2017. Nesse intervalo entre a convocação de reunião do FNE e a sua realização, o MEC mais uma vez atropelou o Fórum e apresentou publicamente a sua proposta de Reforma do Ensino Médio, sem nenhuma consulta àquele espaço. O MEC, desgostoso com o conteúdo do documento-referência elaborado por um conjunto de entidades ligadas à educação, não bancou a reunião do FNE convocada para o mês de fevereiro, anunciando, de forma intempestiva e inédita, que não teria condições de arcar com o deslocamento dos representantes das entidades componentes do FNE para a referida reunião. Mesmo assim, a coordenação do FNE, à época, manteve a reunião agendada e, inclusive distribuiu o documento-referência aos membros do Fórum".

O relatório continua com a epopeia desse embate: "a quatro dias da realização da reunião de fevereiro do FNE, a secretária Maria Helena Machado convocou a coordenação do FNE para uma reunião com o ministro, oportunidade em que o MEC criticou duramente o conteúdo do documento-referência e solicitou o adiamento da reunião do FNE. Como não foram atendidos, os membros do MEC resolveram participar, em peso e em bloco, da reunião do FNE para, explicitamente, fazer a disputa com aquele documento-referência. Na próxima reunião do FNE, convocada para o dia 29 de março com o propósito de revisão do documento-referência, apesar dos apelos das entidades de que as decisões do FNE tinham como hábito ser tomadas por consenso, a proposta do documento-referência foi colocada em votação. Nessa votação, o governo foi derrotado por 23 votos a 9, sendo o documento-referência aprovado pelo plenário do FNE". A partir dessa derrota, o governo golpista fez o que aqui já foi relatado: editou o Decreto adiando a Conae-2018 e a Portaria, que desfigurou a composição do FNE, expulsando várias entidades que ali tinham representação.

Diante desse cenário, explicou Heleno Araújo, "várias entidades decidiram por se retirar do FNE e disputar publicamente, por meio da constituição de um Fórum Nacional Popular de Educação, a realização de uma Conae também de caráter popular. Daí nasce a ideia da Conape. O objetivo nunca foi abrir mão do FNE. A luta das entidades sempre foi pela revogação da Portaria, que, a essa altura, nem vale mais ser feita, já que o calendário das conferências está todo 
atropelado e o governo sequer apresentou um novo documento-referência para balizar os debates e sequer o FNE tem a sua composição nova definida. (...) A ideia da Conape, portanto, nasce como um esforço de manter a mobilização do setor da educação no Brasil, tão atacado pelas medidas do governo golpista de Temer".

A reunião de março foi fundamental para fomentar o caldo de adesão que a Conape passaria a ter a partir de então. Vários fóruns estaduais abandonaram a proposta oficial de realização de uma Conae "para inglês ver", já que essa era, de fato, a real intenção, não confessa, do MEC do governo de Temer. A adesão à Conape foi massiva, em que pese alguns estados terem decidido por manter, concomitante ao esforço de realização da Conape, a participação nas etapas estaduais da Conae oficial.

A reunião assumiu, então, várias definições que, vistas em retrospecto, mostraram seu papel central na construção da conferência popular. Dali, por exemplo, saíram as diretrizes do autofinanciamento da Conape e de sua organização de acolher uma flexibilidade tal que dialogasse com as diferentes realidades vivenciadas por cada um dos fóruns estaduais. Também dessa reunião saiu a orientação de as entidades participantes do FNPE poderem realizar suas conferência livres, com temáticas educacionais que mais lhes interessassem.

A Coordenação Executiva do FNPE estabeleceu, então, um cronograma orientador para a realização das etapas municipais, intermunicipais, estaduais, distrital e nacional da Conape, sempre levando em consideração as condições e realidades particulares de cada estado: até o final de 2017, deveriam ser realizadas as etapas municipais e/ou intermunicipais; até março de 2018, as etapas estaduais e distrital; e em abril de 2018, a Conferência Nacional Popular de Educação (Conape), em Belo Horizonte. Esse cronograma terminou por ser flexibilizado ao longo de seu processo de construção: a etapa nacional, para atender a questão de logística da cidade sede (Belo Horizonte) e das dinâmicas estaduais de realização de suas conferências, foi alterada em sua data de realização para o mês de maio. Mas, a adesão já estava dada. Os números impressionam: até a realização da etapa nacional, que se deu entre os dias 24 e 26 de maio de 2018, a Conape registrou 771 conferências municipais; 24 conferências regionais; 77 conferências intermunicipais; 43 conferências livres; 5 conferências inter-regionais; e 19 conferências estaduais/distrital. De norte a sul do Brasil, a pauta da educação era colocada pelas conferências populares, em um período de nove meses, de setembro de 2017 a maio de 2018. Uma verdadeira gestação, por uma nova educação! 


\section{A etapa nacional da CONAPE: a vitória das entidades da sociedade civil sobre uma agenda privatista de um governo golpista}

A Conape, por fim, foi realizada entre os dias 24 e 26 de maio de 2018, na cidade de Belo Horizonte/MG. Todo o movimento preliminar das conferências municipais, estaduais e livres mobilizou os educadores/as brasileiros/as e depositou na realização de sua etapa nacional uma expectativa alta, condizente, é certo, com toda a trajetória de construção coletiva e da simbologia de uma ação política de resistência aos desmandos do governo Temer.

Cumpre destacar que, desde uma reunião do Pleno do FNPE, ocorrida no dia 17 de fevereiro de 2018, a metodologia da Conape foi alterada para dar conta de uma atividade que se propôs a ser, desde o início, um movimento auto gerido e auto financiado pelas entidades participantes do FNPE. Até então, a organização da Conape estava seguindo os procedimentos adotados pelas experiências anteriores das Conaes, como a inscrição rígida de delegados por segmentos e toda a dinâmica e padrão de emendas ao documento-referência. Essa reunião definiu que a Conape passaria a ser organizada, sobretudo, na perspectiva de um movimento de mobilização do setor educacional brasileiro e de resistência ao golpe. A estimativa de delegados atendeu ao preceito que, de forma soberana e livre, cada entidade pudesse viabilizar, da melhor forma que lhe aprouvesse, o deslocamento e alojamento adequados de suas delegações. Nesse momento, foi indicado, também, que a Conape deveria se encerrar com um Manifesto - Carta de Belo Horizonte, que contivesse um plano de lutas do setor da educação para o próximo período.

A partir daí, toda a organização da Conape se voltou para, de um lado, acolher as emendas ao documento-referência, que balizou os debates travados no âmbitos das conferências municipais, estaduais e livres, e por outro, a construir um sistema de inscrição de delegados, em que fosse possível os estados realizar a inscrição dos nomes de interessados em participar da etapa nacional em Belo Horizonte.

As emendas ao documento-referência sinalizaram o amplo debate travado especialmente no âmbito das conferências estaduais e distrital. Dividido em oito eixos de debate, esse documento trazia um amplo diagnóstico e propostas de intervenção sobre a educação brasileira a partir de um vasto e abrangente temário: cooperação federativa; sistema de avaliação; gestão democrática; acesso e permanência; diversidade e inclusão; políticas intersetoriais; formação, carreira e remuneração; financiamento e gestão da educação. Esse debate muito rico se daria a partir da divisão em grupos para discutir os eixos constantes no documento-referência, previamente publicizado para que todos pudessem dele ter conhecimento. E as emendas, que poderiam ser de três tipos (supressiva, substitutiva e aditiva), perfizeram um total de 2.001 sugestões de alguma alteração ao documento-referência, inscritas por 18 estados da Federação ${ }^{5}$. 
Quanto à natureza das emendas sugeridas pelas etapas preliminares da Conape ao documento-referência, o quadro ficou assim distribuído: das 2.001 emendas, a maior parte delas foi de natureza aditiva, que perfez um total de 1.488 emendas. O segundo tipo de emenda mais presente nos debates prévios da Conape foi de natureza substitutiva, em um total de 367 emendas com propostas de substituição ao texto do documento-referência. Por fim, o texto base da Conape, que guiou todas as discussões nos estados, municípios e Distrito Federal, recebeu apenas 146 emendas supressivas.

Na parte que cabe à inscrição de delegados, a Conape contou com dois momentos de inscrição: em um primeiro momento, os estados sinalizaram com o quantitativo de delegados indicado pelas conferências preliminares (estaduais, municipais, regionais, distrital e livres), mas todos já acautelados de que o deslocamento, hospedagem e alimentação das delegações se dariam conforme o princípio de auto-organização e autofinanciamento da Conape. No primeiro momento de inscrição, com exceção de Tocantins e Roraima, os estados da Federação inscreveram 3.765 delegados.

A maior delegação, com 810 inscritos, foi do próprio estado de Minas Gerais, o que representava 21,5\% do total de inscrições. O estado de São Paulo foi o segundo com maior presença de delegados na primeira fase: 413 inscrições, representando quase 11\% do total. Esses dois estados foram seguidos por Espírito Santo (339 inscrições - 9\%), Bahia (258 inscrições - 6,8\%), Ceará (222 inscrições - 5,9\%) e Pernambuco (219 inscrições $5,8 \%$ ). Os estados com menor número de inscrições foram Amazonas e Acre, ambos com quatro delegados.

O primeiro momento de inscrição de delegados sempre traz o risco da "quebra", fenômeno que demonstra que, no credenciamento da Conferência, no efetivo registro, in loco, o número de delegados credenciados ao evento é sempre inferior ao indicado no primeiro momento. Isso se dá em decorrência de inúmeros fatores que, objetivamente, não permitem que a intenção de o delegado estar presente na Conferência seja confirmada no evento. Esse fenômeno ocorria, inclusive, nas conferências oficiais (Conae), quando todo o custeio de deslocamento e hospedagem do participante era feito pelo governo. Em uma atividade autofinanciada como foi a Conape, a tendência era que essa "quebra" fosse até maior.

No credenciamento da Conape, que ocorreu nos pavilhões da Expominas, em Belo Horizonte, foram credenciados à participação na Conferência 2.444 delegados, 65\% da expectativa inicial a partir do número indicado pelas inscrições. Esta foi, ao fim e ao cabo, a participação final de educadoras e educadores de todo o Brasil na etapa nacional da Conape. De fato, todo o Brasil estava representado na Conferência, inclusive os estados de Tocantins e Roraima, que, no primeiro momento das inscrições, não haviam indicado delegados. E o percentual de "quebra" de 35\% foi até razoável, se se tiver em conta a natureza de autofinanciamento do evento e de um momento peculiar de nossa história política nacional: na semana de realização da Conape, o Brasil se viu diante de 
uma crise de desabastecimento de combustíveis, em decorrência do que ficou conhecido como "greve dos caminhoneiros", um movimento paredista que, embora inicialmente tenha sido uma paralisação em termos de lockout, financiada pelos empresários, parou o País de Norte a Sul, gerando bloqueios em estradas, cancelamentos de voos nos aeroportos e gigantescas filas de veículos nas cidades para abastecimento.

Desse montante de 2.444 delegados credenciados, a expectativa inicial de participação por estado da Federação se manteve em parte: a maior delegação credenciada à Conape continuou sendo a mineira, com 654 delegados inscritos (26,7\%), seguida pelo estado de São Paulo, com 208 delegados (8,5\%). Já o terceiro estado com maior participação na Conape foi Pernambuco, que credenciou 164 delegados (6,71\%). O Distrito Federal alcançou a quarta posição em número de credenciados, com 142 delegados (5,81\%), seguido por Santa Catarina, que contou com 131 delegados (5,36\%).

A primeira Conferência Popular de Educação ocorrida na história do Brasil teve, assim, a seguinte programação: no dia 24 de maio de 2018, uma concentração às 14 h na Praça da Liberdade, com apresentações culturais e falas das entidades locais e nacionais. Às 16h, a marcha da educação abriu a Conape e saiu em direção à Praça da Estação, onde ocorreu a solenidade de abertura oficial, que contou com a presença e fala da presidenta legítima Dilma Rousseff. Já no dia 25 de abril, na parte da manhã, a Conape contou com as atividades autogestionadas e sugeridas pelas entidades participantes e organizadoras da Conferência, no Expominas, e as sessões de comunicação oral, com apresentações de trabalhos acadêmicos, que ocorreram na UFMG. Na parte da tarde desse dia, no Expominas, as plenárias de eixos discutiram os temas prementes da educação brasileira, constantes no documento-referência, e o tom dos debates foi acalorado e produtivo. Educadoras e educadores discutiram os rumos da educação brasileira. A Plenária Final da Conape foi agendada para a parte da manhã do dia 26, e às 14h houve o encerramento da Conferência, com indicações de propostas de luta e de mobilizações em defesa da educação para o próximo período. O retorno das delegações aos estados se deu em clima absolutamente festivo, diante do sucesso da empreitada.

\section{Conape, o Plano Nacional de Educação (PNE) e a urgente construção do Sis- tema Nacional de Educação (SNE)}

Dia 26 de maio de 2018. Encerramento da Conape na Expominas. Céu azul na capital de Minas Gerais. Entretanto, crise em um Brasil de conjuntura conturbada pela greve dos caminhoneiros que paralisou rodovias e aeroportos - tudo que dependia de derivados do petróleo, com desdobramentos para inúmeros outros setores da vida social brasileira. Crise também, e mais profunda, estrutural, gerada por opressões, e 
que reproduz desigualdades cada vez mais insuportáveis. De propriedade, renda e de oportunidades educacionais.

Por que não se cumprem as metas e não se implementam as estratégias do PNE?

Por que o Projeto de Lei Federal, que institui o Sistema Nacional de Educação SNE, não dá um passo no Congresso Nacional?

Por que o MEC se arvorou a intervir na própria composição do Fórum Nacional de Educação?

Esperamos que da leitura histórica e legal do nascimento e do desenvolvimento das conferências de educação e da descrição da Conape recém-realizada, a sociedade brasileira - principalmente os educadores e estudantes - conclua que uma árdua tarefa se impõe: a viabilização política e financeira do PNE como caminho para a construção do SNE.

Neste sentido, duas opções se vislumbram. A primeira é a volta, pelas eleições de outubro de 2018, de um governo com a hegemonia das forças de esquerda, que possa implementar, por cima, as medidas estruturais transformadoras. A principal, sem dúvida, é a do acúmulo de recursos financeiros públicos para se chegar a despender 10\% do PIB em educação até 2024. Essa medida depende de reforma tributária e fiscal que alavanque receitas da União, dos estados, do Distrito Federal e dos municípios, incluindo nos tributos os derivados do Pré-Sal e novos critérios de distribuição, responsabilizando o Governo Federal com proporção maior de recursos.

A segunda opção, perfeitamente cabível com o cumprimento das metas e estratégias dos planos estaduais e municipais de educação, é a da construção, em um movimento inverso ao da primeira opção, de baixo para cima, de políticas e ações subnacionais independentemente da substituição dos donos do poder em Brasília.

Na década de 1980, tivemos a experiência de, em pequenos munícipios do Nordeste, então governados por progressistas e comprometidos com o povo, antecipar a universalização das matrículas no ensino obrigatório com avanços também na EJA e na educação infantil. Nesse sentido, então, é possível e desejável que avancemos nos planos municipais e estaduais. É a arma de que dispomos para fazer avançar a educação em nosso país: a luta pela implementação das metas dos planos municipais, estaduais, distrital e nacional de educação.

A viabilização dessa segunda opção exigirá de todos o empoderamento dos conselhos municipais, estaduais e distrital de educação pela sociedade civil, a partir da presença e ação dos sindicatos de trabalhadores em educação e da comunidade em geral (pais e estudantes). Só dessa forma é possível implementar o efetivo controle social dos recursos destinados à educação púbica e fazer cumprir as metas dos planos, colocando-se em permanente estado de vigilância contra quaisquer possibilidades de captura desses importantes instrumentos de controle social por governos de qualquer orientação política que queiram deles se apossar, como recentemente aconteceu ao Conselho 
Nacional de Educação com o advento do governo golpista. Os conselhos são da sociedade e somente a ela devem se subjugar.

Esses são os dois desafios centrais do atual momento brasileiro que não se excluem, mas que requerem, ambos, uma postura de compromisso dos/as educadores/as, das famílias e dos estudantes, com a opção pela escola pública, universal, laica, democrática e de qualidade, sem a qual PNE e SNE se reduzem a discursos protelatórios e enganosos.

A certeza de que a Conape, em alguma medida, contribuiu com a organização do setor educacional brasileiro para fazer frente ao atual momento de desmonte da educação pública em nosso país alenta os sonhos mais profícuos na defesa de uma educação transformadora e emancipadora do ser humano.

A Carta de Belo Horizonte, manifesto aprovado no último dia da Conape, sinaliza para a realização de uma segunda conferência popular em 2022, além de delinear um importante plano de lutas para o próximo período, tendo sempre em perspectiva o cumprimento das metas do PNE e a expectativa de construção democrática de um SNE. Esse manifesto exige também o fim da interferência do MEC no FNE e defende a reconstituição daquele espaço em sua composição original.

É importante destacar que a Carta de BH assumiu o tom de toda a construção da Conape, aqui retratada: trata-se de um manifesto que toca em questões centrais da educação brasileira, mas não negligencia o entorno que é capaz de promovê-la. Sem democracia, denuncia esse documento histórico, não é possível uma educação pública e de qualidade social; sem democracia, diz o manifesto, não se põe fim aos assassinatos políticos e prisões arbitrárias que estamos a vivenciar no País; sem a retomada do ambiente democrático, não alcançaremos a revogação da Emenda Constitucional n ${ }^{\mathbf{0}}$ 95/2016, que tanto mal faz e fará à educação pública brasileira; sem democracia, não será possível estancar as manifestações fascistas de movimentos como o da Escola sem Partido e das Leis da Mordaça, que se multiplicam nos municípios e estados brasileiros, atentando contra a liberdade de ensinar dos/as educadores/as. Trata-se, portanto, de um documento histórico, construído coletivamente por um movimento do setor educacional brasileiro, que envolveu educadores e estudantes de todos os níveis da educação, da básica à superior, e que se pôs na dianteira da luta por uma "educação democrática, pública, universal, laica, inclusiva, gratuita, democrática, de qualidade social, como direito do/a cidadão/ã e dever do Estado".

\section{Notas}

1 O ex-presidente Luís Inácio Lula da Silva encontra-se preso, no momento da elaboração deste documento, desde o dia 7 de abril de 2018, em um processo judicial marcado pela celeridade diante do calendário eleitoral brasileiro, pela absoluta falta de provas cabais do crime a ele aludido e por um voraz intento persecutório. 
2 Fazem parte do FNPE as seguintes entidades: ABDC; ABGLT; Andifes; Anfope; Anpae; Anped; ANPG; Assinep; Campanha-CNDE; Cedes; CFFa; Conam; CNTE; Confetam; Conif; Contag; Contee; CTB; CUT; Fasubra; Fineduca; Fite; Fitraene/NE; Fórum EJA; Forumdir; Mieib; MNU; MST; Proifes-Federação; RED Estrado; Sinasefe; UBES; UBM; Uncme e UNE.

3 As entidades que compõem a Coordenação Executiva do FNPE foram as seguintes: CUT, CTB, CNTE, Contee, Proifes-Federação, UBES, UNE, Anped, Anpae, Cedes, CNDE e Mieib.

4 Nessa primeira reunião das coordenações estaduais dos fóruns de educação convocada pelo FNPE para organizar e delinear as linhas gerais do que se pretendia com a Conape, estiveram presentes representantes dos seguintes estados da Federação: São Paulo, Santa Catarina, Maranhão, Mato Grosso do Sul, Bahia, Piauí, Ceará, Rio Grande do Norte, Distrito Federal, Mato Grosso, Goiás, Rio de Janeiro, Espírito Santo, Paraná e Pernambuco.

5 Os estados que inseriram emendas ao documento-referência foram os seguintes: Acre, Amapá, Ceará, Bahia, Distrito Federal, Espírito Santo, Goiás, Mato Grosso, Mato Grosso do Sul, Minas Gerais, Pará, Paraíba, Paraná, Rio de Janeiro, Rio Grande do Norte, Rio Grande do Sul, Santa Catarina e São Paulo. 